OPEN ACCESS

Edited by:

Pankaj Kumar Arora

M. J. P. Rohilkhand University, India

Reviewed by:

Shaohua Chen,

Agency for Science, Technology and

Research, Singapore

Janmeajy Pandey,

Central University of Rajasthan, India

${ }^{*}$ Correspondence:

Xiaoke Hu

xkhu@yic.ac.cn

Specialty section:

This article was submitted to Microbiotechnology, Ecotoxicology and Bioremediation,

a section of the journal

Frontiers in Microbiology

Received: 11 May 2017

Accepted: 31 August 2017 Published: 13 September 2017

Citation:

Min J, Chen W, Wang J and HuX (2017) Genetic and Biochemical

Characterization of

2-Chloro-5-Nitrophenol Degradation

in a Newly Isolated Bacterium,

Cupriavidus sp. Strain CNP-8.

Front. Microbiol. 8:1778.

doi: 10.3389/fmicb.2017.01778

\section{Genetic and Biochemical Characterization of 2-Chloro-5-Nitrophenol Degradation in a Newly Isolated Bacterium, Cupriavidus sp. Strain CNP-8}

\author{
Jun Min ${ }^{1}$, Weiwei Chen ${ }^{1}$, Jinpei Wang ${ }^{2}$ and Xiaoke $\mathrm{Hu}^{1 *}$ \\ ${ }^{1}$ Key Laboratory of Coastal Biology and Bioresource Utilization, Yantai Institute of Coastal Zone Research, Chinese Academy \\ of Sciences, Yantai, China, ${ }^{2}$ Key Laboratory of Agricultural and Environmental Microbiology, Wuhan Institute of Virology, \\ Chinese Academy of Sciences, Wuhan, China
}

Compound 2-chloro-5-nitrophenol (2C5NP) is a typical chlorinated nitroaromatic pollutant. To date, the bacteria with the ability to degrade 2C5NP are rare, and the molecular mechanism of 2C5NP degradation remains unknown. In this study, Cupriavidus sp. strain CNP-8 utilizing 2-chloro-5-nitrophenol (2C5NP) and meta-nitrophenol (MNP) via partial reductive pathways was isolated from pesticide-contaminated soil. Biodegradation kinetic analysis indicated that 2C5NP degradation by this strain was concentration dependent, with a maximum specific degradation rate of $21.2 \pm 2.3 \mu \mathrm{M} \mathrm{h}^{-1}$. Transcriptional analysis showed that the mnp genes are up-regulated in both 2C5NP- and MNP-induced strain CNP-8. Two Mnp proteins were purified to homogeneity by Ni-NTA affinity chromatography. In addition to catalyzing the reduction of MNP, MnpA, a NADPH-dependent nitroreductase, also catalyzes the partial reduction of 2C5NP to 2-chloro-5-hydroxylaminophenol via 2-chloro-5-nitrosophenol, which was firstly identified as an intermediate of 2C5NP catabolism. MnpC, an aminohydroquinone dioxygenase, is likely responsible for the ring-cleavage reaction of 2C5NP degradation. Gene knockout and complementation indicated that mnpA is necessary for both 2C5NP and MNP catabolism. To our knowledge, strain CNP-8 is the second 2C5NP-utilizing bacterium, and this is the first report of the molecular mechanism of microbial 2C5NP degradation.

\footnotetext{
Keywords: 2-chloro-5-nitrophenol, catabolism, Cupriavidus sp. strain CNP-8, degradation kinetics, molecular mechanism
}

\section{INTRODUCTION}

Chlorinated nitroaromatic compounds (CNAs) are a group of widely distributed pollutants in the environment throughout the world due to their massive use in the manufacture of herbicides, drugs, dyes and other chemicals (Liu et al., 2011; Tiwari et al., 2017). The natural formation of CNAs is extremely rare. Most of these xenobiotics in the environment are mainly derived from their manufacture, transport and use. Chemical or biological degradation of their derivatives in the environment is another major source. CNAs are highly toxic to humans and animals due 
to their immunotoxicity, hematotoxicity, teratogenicity and carcinogenicity (Arora et al., 2012a, 2014a). Therefore, many CNAs are listed as priority pollutants by the United State Environmental Protection Agency (USEPA). Recently, removal of these toxicants from the environment has aroused wide concern.

Chloronitrophenols (CNPs) including 2-chloro-4nitrophenol (2C4NP), 2-chloro-5-nitrophenol (2C5NP), 4-chloro-2-nitrophenol (4C2NP), and 4-chloro-3-nitrophenol (4C3NP) etc are the typical representative of CNAs. They have been detected in industrial effluents and groundwater in many countries, including China. Physico-chemical methods such as photo-fenton process hve been used to remove CNPs from the water; however, this method is cost-consuming and can not degrade CNPs completely (Pradhan et al., 2013). In contrast, biotreatment is considered to be a more cost-effective and thorough strategy to eliminate CNPs from wastewater. Microbial degradation processes of CNPs are particularly being investigated because they can be effectively coupled with the traditional activated sludge process. However, microbial degradation of CNPs is difficult as the simultaneous existence of electron-withdrawing chloro and nitro groups on the aromatic ring makes thses compounds resistant to microbial attack. Therefore, isolation of CNPs-degraders is of great scientific and industrial significance for the detoxification of these toxicants-containing wastewaters.

In addition to bacterial isolation, the knowledge of microbial degradation mechanism of CNPs is also very important, as a comprehensive understanding of microbial catabolic pathway of the target pollutant at biochemical and genetic level would provide valuable insight on understanding the fate of the pollutant in the environments, as well as assessing the population of the functional bacteria during bioremediation (Chi et al., 2013; Wang et al., 2014; Min et al., 2017). So far, several pure microorganisms have been isolated based on their ability to degrade CNPs. Arthrobacter sp. SJCon (Arora and Jain, 2011), Burkholderia sp. SJ98 (Pandey et al., 2011), Burkholderia sp. RKJ 800 (Arora and Jain, 2012a), Cupriavidus strain a3 (Tiwari et al., 2017), and Rhodococcus imtechensis RKJ 300 (Ghosh et al., 2010) were reported to utilize 2C4NP. Recently, we have revealed the degradation mechanism of 2C4NP in strains SJ98 (Min et al., 2014) and RKJ 300 (Min et al., 2016b). Exiguobacterium sp. PMA was reported to utilize 4C2NP as a sole carbon and energy source and degrade 4C2NP with the formation of 4-chloro-2aminophenol and 2-aminophenol as the intermediates (Arora et al., 2012b). Pseudomonas sp. N31 with a plasmid carrying the genes for chlorocatechol degradation was also reported to utilize 4C2NP (Bruhn et al., 1988). In addition, Bacillus subtilis RKJ 700 (Arora, 2012), Pseudomonas sp. JHN (Arora and Bae, 2014) and Bacillus sp. strain MW-1 (Arora and Jain, 2012b) were reported to transform 4C2NP into 5-chloro-2-methyl benzoxazole. Recently, strain JHN was also proved to be able to utilize $4 \mathrm{C} 3 \mathrm{NP}$ as a sole carbon and energy source and degrade it with the formation of 4-chlororesorcinol as a metabolite (Arora et al., 2014b).

As another typical representative of CNPs, 2C5NP have also been widely used as intermediates of synthesis of chemical products. Due to its non-volatility and long half-life similar to other nitrophenols (Jaoui et al., 2002; Xiao et al., 2007), 2C5NP is a long-lived pollutant in the environment. The presence of ringinactivating chloro and nitro groups may makes it recalcitrant to chemical transformation in the natural environment, and microorganisms were proposed to play an more important role in degrading $2 \mathrm{C} 5 \mathrm{NP}$. Although $2 \mathrm{C} 5 \mathrm{NP}$ is the structural analog of $2 \mathrm{C} 4 \mathrm{NP}, 2 \mathrm{C} 5 \mathrm{NP}$ is more difficult to be degraded by microorganisms. The aromatics with nitro group at meta position are considered to be more resistant to microbial attack than the compounds that have nitro group at para position (Arora et al., 2012b). To date, only one bacterium, Cupriavidus pinatubonensis JMP134 (formerly Cupriavidus necator JMP134 or Ralstonia eutropha JMP134), was reported to degrade 2C5NP (Schenzle et al., 1999b), and the molecular mechanism of 2C5NP degradation remains unknown.

In this study, Cupriavidus sp. strain CNP-8 was isolated based on its ability to utilize 2C5NP as a sole source of carbon and nitrogen. Biodegradation analysis demonstrated that it is a potential and efficient candidate for biotreatment of 2C5NPcontaining industrial effluents. The $m n p$ gene cluster involved in the catabolism of 2C5NP was identified from this strain, and the functions of two genes were verified in vitro and in vivo. Strain CNP-8 isolated here is the second 2C5NP utilizer, and this is the first report of the molecular mechanism of microbial 2C5NP degradation.

\section{MATERIALS AND METHODS}

\section{Bacteria, Plasmids, Primers, Media, and Culture Conditions}

The plasmids and bacteria are in Table $\mathbf{1}$, and the primers are in Table S1. Cupriavidus strains were grown at $30^{\circ} \mathrm{C}$ in minimal salt medium (MSM, omitting the $\mathrm{CaCl}_{2}$ ) (Xiao et al., 2006) with different substrates (2C5NP was dissolved in MSM with initial concentration of $5 \mathrm{mM}$ ). E. coli strains were grown in lysogeny broth (LB) medium at $37^{\circ} \mathrm{C}$. When required, chloramphenicol $(34 \mu \mathrm{g} / \mathrm{ml})$, tetracycline hydrochloride (10 $\mu \mathrm{g} / \mathrm{ml})$ and kanamycin $(50 \mu \mathrm{g} / \mathrm{ml})$ was added to the medium. All reagents used here were purchased from Sigma Chemical Co. (St. Louis, MO).

\section{Isolation and Characterization of 2C5NP Degrader}

Strain CNP-8 was isolated from the pesticide-contaminated soil collected from Yantai, China, by enrichment culture method (Liu et al., 2005). This strain was identified by 16S rRNA sequencing with universal primers $27 \mathrm{~F}$ and $1492 \mathrm{R}$ (Polz and Cavanaugh, 1998). Its morphology was observed by scanning electron microscopy (Model S-4800, Hitachi Ltd., Japan).

\section{C5NP Degradation Studies}

Degradation of 2C5NP by strain CNP-8 was investigated by monitoring the $\mathrm{OD}_{600}$ and the consumption of substrate. Ammonia concentration was quantified colorimetrically by the Nessler reaction (Krug et al., 1979), and chloride ion was determined by using an ion-selective chloride electrode (Model 96-17, Orion). Degradation of different concentrations 
TABLE 1 | Bacterial strains and plasmids used in this study.

\begin{tabular}{|c|c|c|}
\hline Strain or plasmid & Relevant genotype or characteristic(s) & source \\
\hline \multicolumn{3}{|l|}{ Cupriavidus sp. } \\
\hline CNP-8 & 2C5NP and MNP utilizer, wild type & This study \\
\hline CNP-8 $\Delta m n p A$ & CNP-8 mutant with mnpA gene deleted & This study \\
\hline CNP-8 $\Delta m n p A[p R K 415-p n p A]$ & mnpA gene was complemented by pRK415-mnpA in CNP-8 $\Delta m n p A$ & This study \\
\hline \multicolumn{3}{|l|}{ E. coli strains } \\
\hline $\mathrm{DH} 5 \alpha$ & supE44 lacU169 ( $\varphi 80$ lacZ $\Delta \mathrm{M} 15)$ recA1 endA1 hsdR17 thi-1 gyrA96 relA1 & Novagen \\
\hline Rosetta(DE3)pLysS & $\mathrm{F}^{-}$ompthsdS $\left(\mathrm{r}_{\mathrm{B}}^{-} \mathrm{m}_{\mathrm{B}}^{+}\right) \mathrm{gal} d \mathrm{~cm}$, lacY1(DE3) pLysSRARE $\left(\mathrm{Cm}^{\mathrm{r}}\right)$ & Novagen \\
\hline WM3064 & 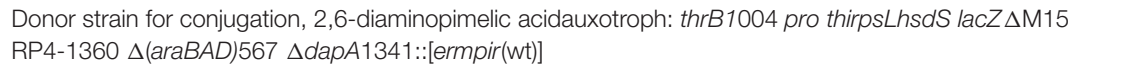 & Lab stock \\
\hline \multicolumn{3}{|l|}{ PLASMIDS } \\
\hline pET-28a & Expression vector, $\mathrm{Kan}^{\mathrm{R}}$ & Novagen \\
\hline pEX18Tc & Gene knockout vector, oriT ${ }^{+}, \operatorname{sacB}^{+}, \mathrm{Tc}^{\mathrm{R}}$ & Lab stock \\
\hline pRK415 & Broad host range vector, $T_{c}^{R}$ & Lab stock \\
\hline pTnMod-Okm & Source of kanamycin resistance gene nptll & Lab stock \\
\hline pET-mnpA & Ndel-Xhol fragment containing mnpA cloned into pET-28a & This study \\
\hline pET-mnpB & Ndel-Xhol fragment containing mnpB cloned into pET-28a & This study \\
\hline pET-mnpC & Ndel-Xhol fragment containing mnpC cloned into pET-28a & This study \\
\hline pET-mnpD & Ndel-Xhol fragment containing $m n p D$ cloned into pET-28a & This study \\
\hline pEX18Tc-mnpA & $\begin{array}{l}m n p A \text { gene knockout vector containing two DNA fragments homologous to the upstream and downstream } \\
\text { regions of the } m n p A \text { and } n p t / l\end{array}$ & This study \\
\hline pRK415-mnpA & mnpA gene complementation vector by cloning $m n p A$ into the $K p n l / E c o R I$ restriction site of pRK415 & This study \\
\hline
\end{tabular}

of 2C5NP (0.3-0.7 mM) by strain CNP-8 was carried out to study the degradation kinetics. The values of kinetic parameters were derived from modified Gompertz model (Fang et al., 2007; Deng et al., 2016) which could be expressed as follows:

$$
S=S_{0}-A^{*} \exp \left\{-\exp \left[\frac{\mu_{\mathrm{m}}}{A}(\lambda-t)+1\right]\right\}
$$

$S$ is the substrate concentration. $S_{0}$ is the initial substrate concentration. $A$ is the biodegradation potential. $\mu_{m}$ is the maximum biodegradation rate. $\lambda$ is the lag phase time.

Different carbon source $(0.5$ and $5 \mathrm{~g} / \mathrm{L}$ of glucose, succinate or lactate) was added to MSM containing $0.4 \mathrm{mM}$ of $2 \mathrm{C} 5 \mathrm{NP}$ to investigate their effect on 2C5NP degradation by strain CNP-8. Biotransformation of meta-nitrophenol (MNP) and 2C5NP by strain CNP-8 was carried out as described (Chen et al., 2014). Quantification of 2C5NP and MNP were performed by HPLC analysis. In order to identify the intermediates of 2C5NP degraded by strain CNP-8, $2 \mathrm{C} 5 \mathrm{NP}$ was incubated under anaerobic condition with $2 \mathrm{C} 5 \mathrm{NP}-$ induced cells, and the metabolites were identified by GC-MS analysis.

\section{Analytical Methods}

HPLC assay was performed as previously described (Min et al., 2016a). MNP and 2C5NP were quantified at 280. The authentic MNP and 2C5NP had retention times of 10.5 and $13.4 \mathrm{~min}$, respectively. The HPLC-MS condition was the same as described previously (Min et al., 2016a) except the gradient mobile phase was different. The mobile phase consisted of A (acetonitrile) and $\mathrm{B}\left(\mathrm{H}_{2} \mathrm{O}\right)$ with the following gradients: $0-5 \mathrm{~min}, 5 \% \mathrm{~A}$; 5-10 min, 5-20\% A; 10-20 min, 20-40\% A; 20-25 min, 40\% A. The condition of GC-MS analysis was the same as described previously (Zhang J. J. et al., 2009).

\section{Real-Time Quantitative PCR, Gene Cloning, Protein Expression and Purification}

Whole-genome sequencing and annotation of strain CNP-8 was performed in the Novogene Bioinformatics Institute (Beijing, China). The transcriptional levels of mnp genes were performed by real-time quantitative PCR (RT-qPCR) as described (Min et al., 2016a) with primers described in Table S1. The relative expression levels of target genes were calculated according to the $2^{-\Delta \Delta C_{T}}$ method with the $16 \mathrm{~S}$ rRNA as a reference gene (Livak and Schmittgen, 2001). mnpA, mnpB, mnpC, and $m n p D$ genes amplified from the genomic DNA (the primers are listed in Table S1), were respectively cloned into pET-28a to obtain the expression plasmids (Table 1). The expression plasmids were subsequently introduced into E. coli Rosetta(DE3)pLysS, and the protein expression and purification was performed as previously described (Liu and Zhou, 2012).

\section{Enzymatic Assays}

The catalytic activity of MnpA against 2C5NP and MNP was analyzed in the reaction mixture $(1 \mathrm{ml})$ containing, $0.2 \mathrm{mM}$ NADPH, $0.1-5 \mu \mathrm{g}$ of purified $\mathrm{H}_{6}-\mathrm{MnpA}, 50 \mu \mathrm{M}$ substrate (2C5NP or MNP) and $50 \mathrm{mM}$ phosphate buffer ( $\mathrm{pH} 7.5$ ). The reference cuvette contained all components except the substrate, and the activity assay was initiated with the addition of substrate. During identification of products, the experiment was 
performed under anaerobic conditions to prevent autoxidation of the products. The reaction mixture was extracted with ethyl acetate after $\mathrm{HCl}$ acidification, and the ethyl acetate phase was then collected and dried using anhydrous sodium sulfate before HPLC-MS analysis. In the kinetics assays, three independent experiments were carried out with 7 substrate concentrations (2C5NP: 5-50 $\mu \mathrm{M}$; MNP: 2-20 $\mu \mathrm{M}$ ), while the concentration of NADPH was fixed at $200 \mu \mathrm{M}$. The MichaelisMenten equation was fitted to the data by using OriginPro 8. Bradford method (Bradford, 1976) was used to determine the protein concentration. One unit of enzyme activity was defined as the amount of enzyme consuming $1 \mu \mathrm{mol}$ of substrate (2C5NP or MNP) in $1 \mathrm{~min}$. The dioxygenase activity of MnpC toward hydroquinone and chlorohydroquinone was measured as described for aminohydroquinone dioxygenase (Yin and Zhou, 2010).

\section{Gene Knockout and Complementation of mnpA}

Gene knockout and complementation were performed as previously described (Min et al., 2014). Plasmid pEX18Tc$m n p A$ for $m n p A$ knockout was constructed by fusing kanamycin resistance gene (nptII) and the upstream and downstream fragments of mnpA to EcoRI/HindIII digested pEX18Tc by using in-fusion HD cloning kit (Takara) (the primers are listed in Table $\mathrm{S} 1$, and the plasmids are in Table 1). Plasmid pRK415-mnpA used for $m n p A$ complementation was obtained by cloning $m n p A$ to the HindIII/KpnI digested pRK415. The ability of strains CNP$8 \Delta m n p A$ and CNP-8 $\Delta m n p A[\mathrm{pRK} 415-m n p A]$ to utilize substrate (2C5NP or MNP) was examined by determining bacterial growth and substrate consumption.

\section{Nucleotide Sequence Accession Numbers}

The GenBank accession numbers for the nucleotide sequence of $16 \mathrm{~S}$ rRNA, mnp gene cluster and $m n p B$ gene reported in this paper are KY643479, KY937901, and KY937902, respectively.

\section{RESULTS AND DISCUSSION}

\section{Isolation and Classification of Strain CNP-8}

A 2C5NP-degrading bacterium, designated strain CNP-8, was isolated from pesticide-contaminated soil with $2 \mathrm{C} 5 \mathrm{NP}$ as a sole source of carbon and nitrogen. It was characterized as Gramnegative by Gram staining, and observed as short-rod-shaped by scanning electron microscopy (Figure 1A). It was identified as a member of Cupriavidus based on 16S rRNA sequence analysis. The phylogenetic relationships of the 16S rRNA gene sequences of strain CNP-8 and other representative Cupriavidus strains are shown in Figure 1B. Before this study, there is only one bacterium, Cupriavidus pinatubonensis JMP134 (Schenzle et al., 1999b), was reported to be able to degrade 2C5NP.

\section{Biodegradation of 2C5NP by Strain CNP-8 Strain CNP-8 Degrades 2C5NP with Release of Ammonium and Chloride lon}

Strain CNP-8 degraded $0.3 \mathrm{mM}$ of 2 C5NP completely after $36 \mathrm{~h}$ of incubation with release of ammonium and chloride ion (Figure 2A). Meanwhile, the biomass increased apparently, with $\mathrm{OD}_{600}$ increasing from initial 0.048 to final 0.146 . This clearly revealed that strain $\mathrm{CNP}-8$ is capable to utilize $2 \mathrm{C} 5 \mathrm{NP}$ as sole sources of carbon and nitrogen, and the cell growth was closely correlated with the amount of substrate utilized. In particular, the cell growth exhibited a lag phase of about $12 \mathrm{~h}$, and then increased rapidly for the rest of the incubation period, indicating that strain CNP-8 had an induction period prior to utilize $2 \mathrm{C} 5 \mathrm{NP}$. In addition to 2C5NP, strain CNP-8 was also found to be able to utilize MNP with the release of ammonium, and the $\mathrm{OD}_{600}$ increased from 0.051 to 0.162 within $20 \mathrm{~h}$ (Figure 2B). The higher degradation rate of MNP than 2C5NP is apparently due to that $2 \mathrm{C} 5 \mathrm{NP}$ is much more recalcitrant and toxic as compared to MNP. As ammonium was released during the catabolism of both 2C5NP and MNP, strain CNP-8 was assumed to degrade these two nitrophenols via the partial reductive pathways.

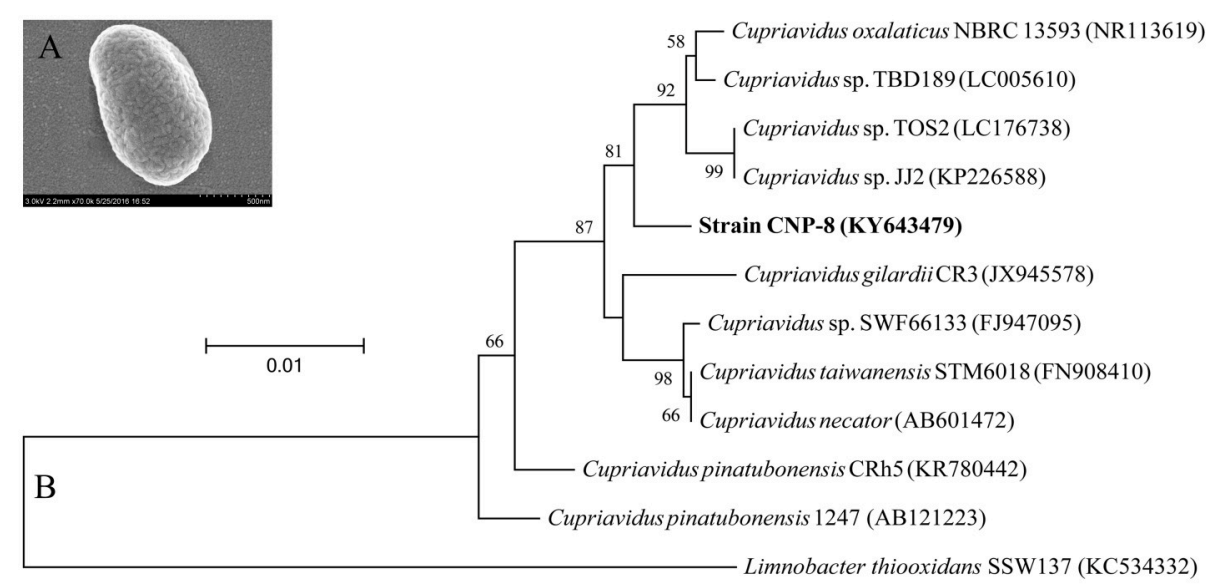

FIGURE 1 | Identification of the newly isolated Cupriavidus sp. strain CNP-8. (A) The morphological observation of strain CNP-8 by scanning electron microscopy. (B) The phylogenetic tree of strain CNP-8 based on 16S rRNA gene sequence analysis. Limnobacter thiooxidans SSW137 was used as outgroup. GenBank accession numbers are shown in parentheses. 

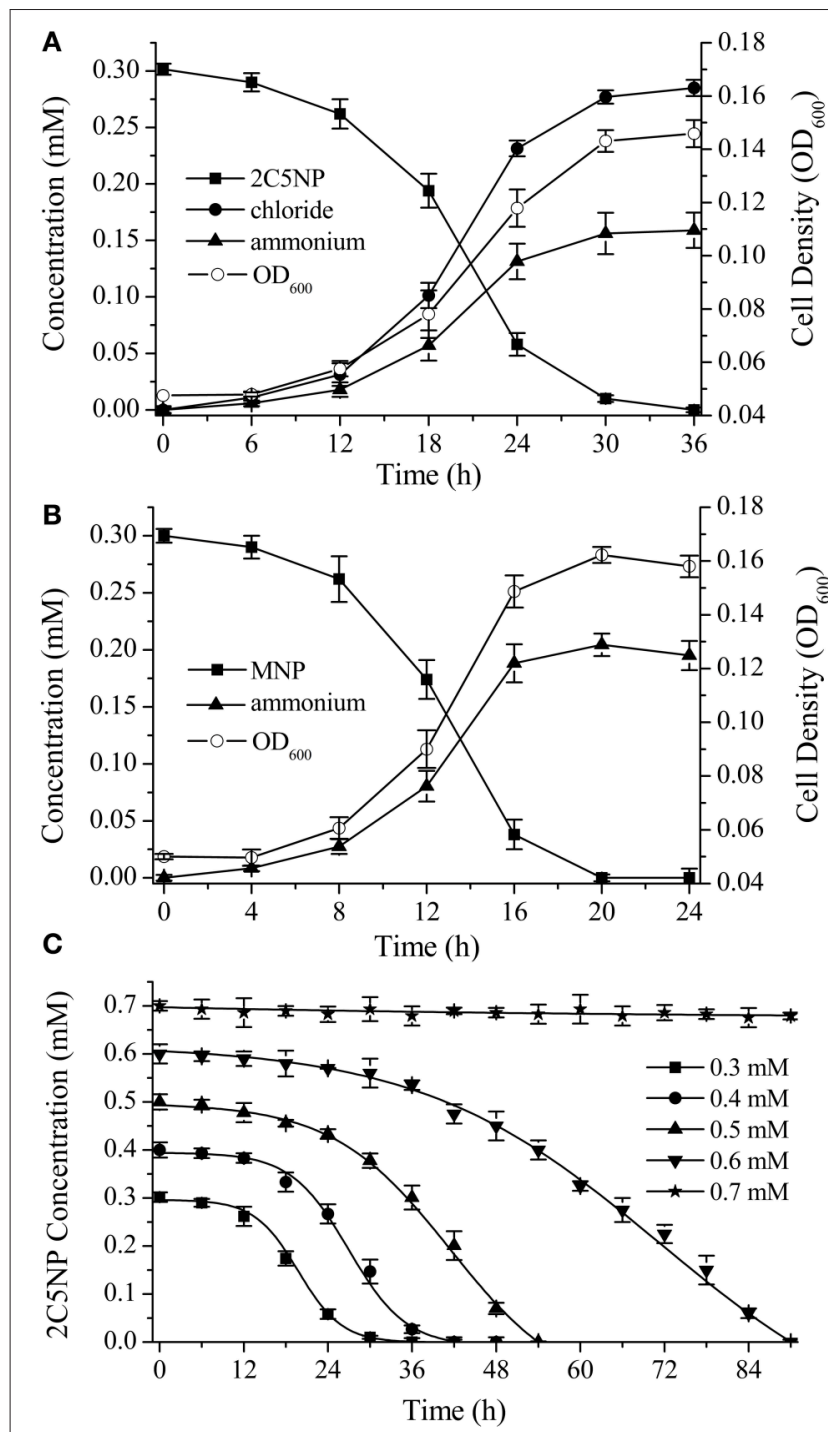

FIGURE 2 | Biodegradation of 2C5NP (A) and MNP (B) by Cupriavidus sp. strain CNP-8, together with the accumulation of chloride, ammonia and the bacterial biomass (indicated by $\mathrm{OD}_{600}$ ). (C) Effect of different 2C5NP concentrations on 2C5NP biodegradation by strain CNP-8. All experiments were performed in triplicate with initial $\mathrm{OD}_{600}$ of approximately 0.05 . Error bars indicate standard deviations.

\section{C5NP Degradation Kinetics}

Biodegradation of 2C5NP at different concentrations was carried out to determine the kinetic parameters of 2C5NP degradation by strain CNP-8. This knowledge is important in understanding the capability of the degrader and designing the bioremediation process (Shen et al., 2009). Because the growth of strain CNP-8 was coupled to the $2 \mathrm{C} 5 \mathrm{NP}$ consumption, the substrate biodegradation can be quantitatively characterized using a modified Gompertz model (Fang et al., 2007; Deng et al., 2016). As shown in Figure 2C, strain CNP-8 degraded $0.3 \mathrm{mM}$ of 2C5NP completely in $36 \mathrm{~h}$, followed by $0.4 \mathrm{mM}$ in $42 \mathrm{~h}, 0.5 \mathrm{mM}$ in $54 \mathrm{~h}$, and $0.6 \mathrm{mM}$ in $90 \mathrm{~h}$. Accelerated biodegradation of 2C5NP was described well by the modified Gompertz model, with $\mathrm{R}^{2}$ more than $98.8 \%$ (Table 2 ). The biodegradation lag phase was prolonged apparently with the increase of $2 \mathrm{C} 5 \mathrm{NP}$ concentration, and the maximum biodegradation rate was 21.2 $\pm 2.3 \mu \mathrm{M} \mathrm{h}^{-1}$ when the substrate concentration was $0.4 \mathrm{mM}$. However, negligible degradation of $2 \mathrm{C} 5 \mathrm{NP}$ was observed when the substrate exceeded $0.7 \mathrm{mM}$. This indicated that $2 \mathrm{C} 5 \mathrm{NP}$ at high concentrations exhibited toxic inhibitory effect on growth of strain CNP-8. Indeed, microbial degradation of chloronitrophenols such as 2C4NP (Arora and Jain, 2012a; Tiwari et al., 2017) and 4C2NP (Arora et al., 2012b), as the isomers of $2 \mathrm{C} 5 \mathrm{NP}$, has been proved to be concentration dependent.

\section{Effect of Supplemented Carbon on 2C5NP Degradation}

Different concentrations of glucose, succinate or lactate were supplemented to MSM with $0.4 \mathrm{mM}$ of $2 \mathrm{C} 5 \mathrm{NP}$ to investigate the effect of additional carbon sources on the degradation of 2C5NP by strain CNP-8. This is of practical importance for biotreatment of 2C5NP-containing industrial wastewater or soil because several reports have shown that nutrient supplement can stimulate growth of pollutant degraders and enhance their ability to degrade contaminants (Cheung and Kinkle, 2005; Zhong et al., 2007), while some other studies have claimed that changes in nutrients could produce negative effects (Carmichael and Pfaender, 1997; dos Santos et al., 2009). In this study, addition of all nutrients with concentration of $0.5 \mathrm{~g} / \mathrm{L}$ enhanced the degradation of 2C5NP, and succinate addition exhibited maximum degradation rates (Table 3). However, the 2C5NP degradation was found to be inhibited when the concentration of nutrient was increased up to $5 \mathrm{~g} / \mathrm{L}$, although the biomass increased remarkably. This indicated that supplemental nutrient could enhance 2C5NP degradation as a result of increase in biomass, but in a dose dependent manner. This is similar with the report of para-nitrophenol degradation by Rhodococcus sp. strain CN6 (Zhang J. et al., 2009). A more interesting finding is that strain CNP-8 was found to be able to remove $0.7 \mathrm{mM}$ of $2 \mathrm{C} 5 \mathrm{NP}$ in $90 \mathrm{~h}$ when $0.5 \mathrm{~g} / \mathrm{L}$ of succinate was added, although it is unable to grow on MSM containing only the same amount of substrate. We speculate that the simultaneous utilization of supplemental nutrients and 2C5NP enables strain CNP-8 to mitigate the 2C5NP toxicity by available nutrient and consequently by the build-up of more biomass. This hypothesis has been proposed previously to explain the degradation of phenol (dos Santos et al., 2009). Herein, the degradation of 2C5NP by strain CNP-8 was investigated in liquid MSM whose composition was similar with some reported synthetic wastewater (Ahmadi et al., 2015; Tiwari et al., 2017); therefore, the result in this study is likely able to extrapolate to the real wastewater.

\section{C5NP Degradation Is Induced by either 2c5np or MNP}

Considering that strain CNP-8 degraded both MNP and 2C5NP via partial reductive pathways; therefore, biotransformation analysis was initially carried out to determine whether the metabolism of 2C5NP and MNP share the enzymes. The uninduced strain CNP-8 had no activity for both 2C5NP and MNP 
TABLE 2 | Kinetic parameters of 2C5NP degradation by strains CNP-8.

\begin{tabular}{lcccc}
\hline Strains & $\begin{array}{c}\text { Initial } \\
\text { 2C5NP }(\boldsymbol{\mu} \mathbf{M})\end{array}$ & $\boldsymbol{\lambda}$ (h) $)^{\mathbf{a}}$ & $\begin{array}{c}\mathbf{e m p h} \boldsymbol{\mu m}_{\mathbf{m}} \\
\left(\boldsymbol{\mu} \mathbf{M ~ h} \mathbf{~}^{-\mathbf{1}}\right)^{\mathbf{b}}\end{array}$ & $\boldsymbol{R}^{\mathbf{2}}$ \\
\hline CNP-8 & 302 & $12.1 \pm 0.8$ & $20.0 \pm 1.6$ & 0.988 \\
& 409 & $16.3 \pm 1.3$ & $21.2 \pm 2.3$ & 0.988 \\
& 504 & $24.9 \pm 1.0$ & $17.7 \pm 1.6$ & 0.995 \\
& 610 & $32.9 \pm 1.8$ & $11.9 \pm 1.1$ & 0.991 \\
CNP-8 4 mnpA & 404 & $15.5 \pm 1.7$ & $14.7 \pm 0.8$ & 0.989 \\
[PRK415-mnpA] & & & & \\
\hline
\end{tabular}

Minimal salt medium (MSM) with different concentrations of 2C5NP was inoculated by strain CNP-8 with initial $O D_{600}$ of 0.05 , and shaken at $30^{\circ} \mathrm{C}$ and $180 \mathrm{rpm} .{ }^{a} \lambda$ is the lag phase time. ${ }^{b} \mu_{m}$ is the maximum biodegradation rate.

TABLE 3 | Effect of different carbons on degradation of 2C5NP by strain CNP-8.

\begin{tabular}{lcccc}
\hline $\begin{array}{l}\text { Carbon } \\
\text { source }\end{array}$ & $\begin{array}{c}\text { Concentration } \\
\mathbf{( g / L )}\end{array}$ & $\mathbf{O D}_{\mathbf{6 0 0}}{ }^{\mathbf{a}}$ & $\begin{array}{c}\text { Time required for } \\
\text { complete } \\
\text { degradation of } \\
\mathbf{2 C 5 N P}(\mathbf{h})\end{array}$ & $\begin{array}{c}\text { Degradation } \\
\text { rate }\left(\boldsymbol{\mu} \mathbf{M ~ h} \mathbf{~}^{-1}\right)^{\mathbf{b}}\end{array}$ \\
\hline Control & - & $0.171 \pm 0.012$ & $42.4 \pm 2.5$ & 9.43 \\
\hline glucose & 0.5 & $0.332 \pm 0.026$ & $24.7 \pm 1.6$ & 16.19 \\
& 5 & $1.587 \pm 0.035$ & $60.1 \pm 2.4$ & 6.65 \\
\hline succinate & 0.5 & $0.354 \pm 0.018$ & $22.5 \pm 2.1$ & 17.78 \\
& 5 & $1.632 \pm 0.027$ & $53.3 \pm 3.8$ & 7.50 \\
\hline lactate & 0.5 & $0.312 \pm 0.032$ & $26.5 \pm 1.4$ & 15.09 \\
& 5 & $1.534 \pm 0.024$ & $63.4 \pm 3.5$ & 6.31 \\
\hline
\end{tabular}

Minimal salt medium (MSM) with $0.4 \mathrm{mM}$ of 2C5NP was inoculated by strain CNP-8 with initial $O D_{600}$ of 0.05 , and shaken at $30^{\circ} \mathrm{C}$ and $180 \mathrm{rpm}$. Control: without added carbon source.

a $O D_{600}$ was determined at the time of complete degradation of 2C5NP.

${ }^{b}$ Rate of $2 \mathrm{C} 5 \mathrm{NP}$ degradation $\left(\mu \mathrm{M} \mathrm{h}^{-1}\right)=400 /$ time required for complete degradation of 2C5NP.

(Figures 3A,B), whereas the 2C5NP-induced cells degraded $2 \mathrm{C} 5 \mathrm{NP}$ with a rate of $5.22 \pm 0.47 \mu \mathrm{M} / \mathrm{OD}_{600}$ of cell/min and MNP-induced cells degraded MNP with a rate of $10.34 \pm 1.21$ $\mu \mathrm{M} / \mathrm{OD}_{600}$ of cell/min, indicating that the genes responsible for $2 \mathrm{C} 5 \mathrm{NP}$ and MNP degradation in strain CNP-8 were inducible. Furthermore, MNP-induced cells can degrade 2C5NP (8.35 \pm $0.87 \mu \mathrm{M} / \mathrm{OD}_{600}$ of cell $/ \mathrm{min}$ ), while $2 \mathrm{C} 5 \mathrm{NP}$-induced strain CNP-8 was found to be able to transform $\mathrm{MNP}\left(6.01 \pm 0.54 \mu \mathrm{M} / \mathrm{OD}_{600}\right.$ of cell $/ \mathrm{min}$ ). This suggests that the enzymes involved in $2 \mathrm{C} 5 \mathrm{NP}$ degradation are likely also responsible for the catabolism of MNP in strain CNP-8. No intermediate was detected when strain CNP-8 was grown in MSM with 2C5NP as sole sources of carbon and nitrogen. However, a metabolite was captured by GC-MS analysis when 2C5NP was incubated under anaerobic condition with 2C5NP-induced cells. This intermediate was proposed as aminohydroquinone based on the molecular ion peak at m/z 125 (Figure S1).

\section{Sequence Analyses of 2C5NP Catabolic Genes}

The above finding revealed that metabolism of $2 \mathrm{C} 5 \mathrm{NP}$ and MNP in strain CNP-8 may share identical enzymes, which

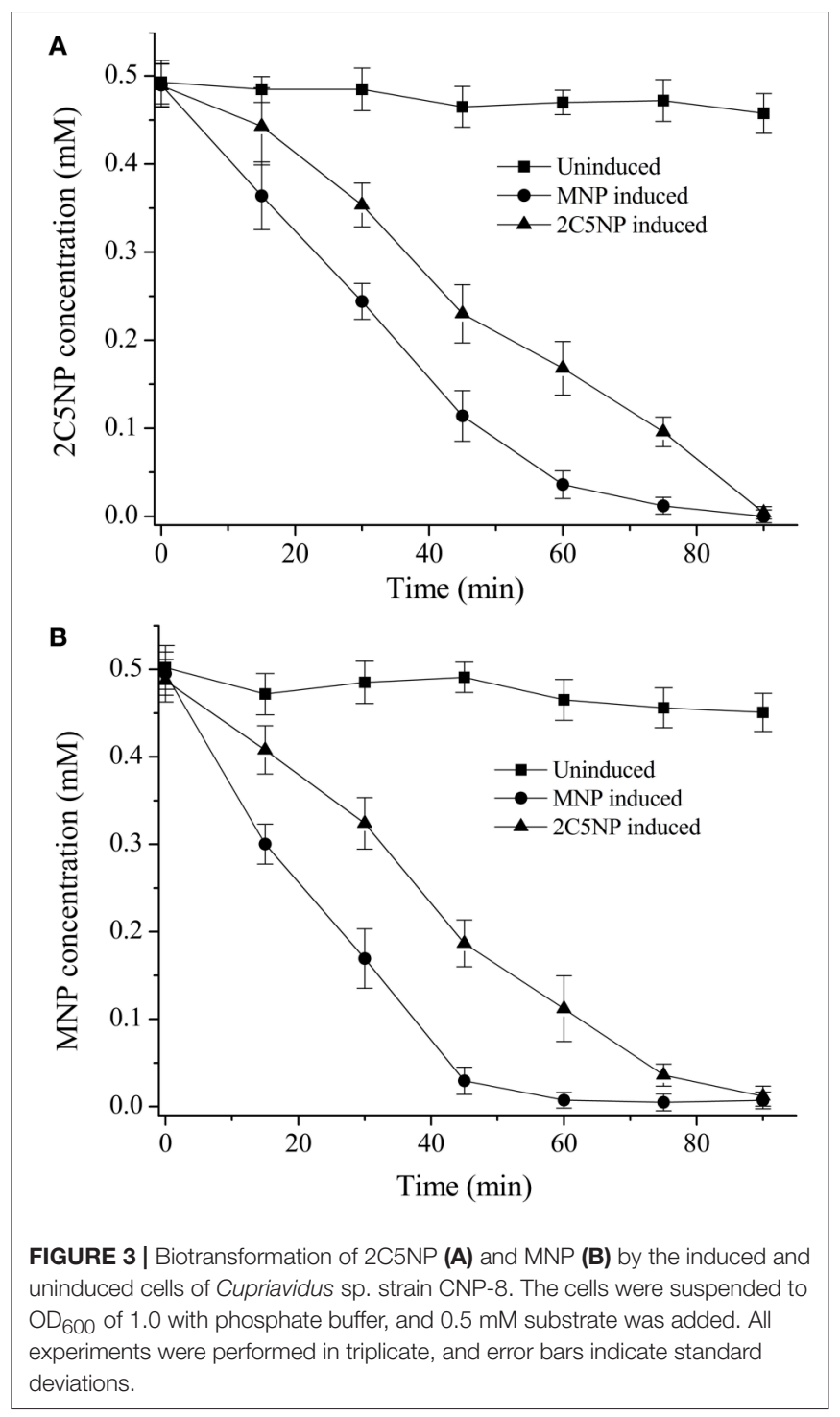

motivate us to identify their coding genes. This knowledge is very significant because the molecular mechanism of microbial 2C5NP degradation remains unknown. Initially, the draft genome of strain CNP-8 was sequenced. A gene cluster designated as $m n p$ (Figure 4A) was identified from the contig 80 by comparative genomics analysis with Cupriavidus pinatubonensis JMP134. The proteins encoded by mnpA and mnpC exhibit high homology with MNP nitroreductase (93\% identity) (Yin et al., 2010) and aminohydroquinone dioxygenase (94\% identity) (Yin and Zhou, 2010), respectively, which were reported to be involved in MNP catabolism in strain JMP134. $m n p D$ appears to encode a reductive dechlorinase belong to the glutathione S-transferase family as the level of identity of MnpD with the 2,5-dichlorohydroquinone reductive dehalogenase from Sphingomonas paucimobilis UT26 is 40\% (Kumari et al., 2002). $\mathrm{MnpR}, \mathrm{MnpE}$, and MnpF were proposed to be LysR regulatory protein, amidase and maleylacetate reductase, respectively, by BLAST analysis with the available genome sequence of strain 


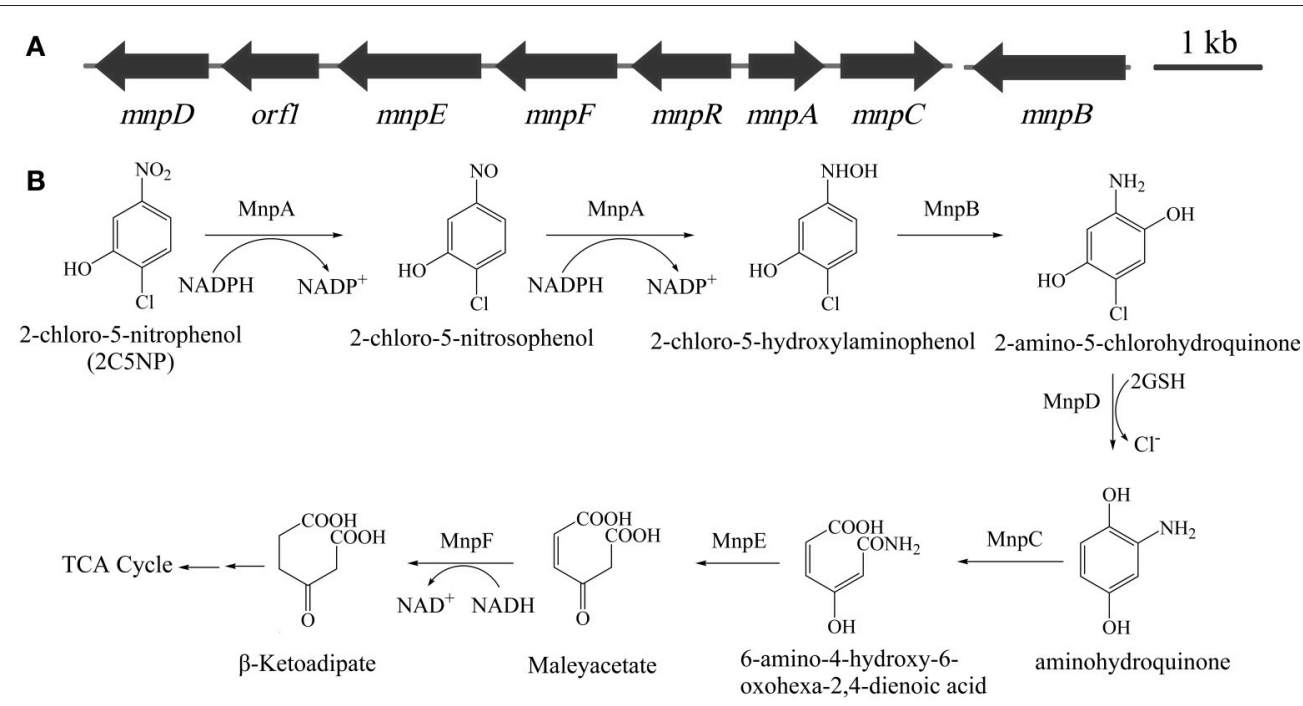

FIGURE 4 | (A) Organization of the mnp gene cluster of Cupriavidus sp. strain CNP-8. The black arrows indicate the sizes and directions of transcription of each gene. (B) Proposed pathway for 2C5NP catabolism in strain CNP-8, together with the catabolic reactions catalyzed by mnp gene products.

JMP134. In addition, a gene (designed as $m n p B$ ) encoding a protein with $99 \%$ of identity with the 3-hydroxylaminophenol mutase involved in MNP catabolism in strain JMP134 (Schenzle et al., 1999a) was identified from the contig 35 by comparative genome analysis.

\section{mnp Genes Are Up-Regulated in 2C5NP-Induced Strain CNP-8}

RT-qPCR showed that the transcription levels of $m n p A$, $m n p B, m n p C$, and $m n p D$ under 2C5NP-induced condition were significantly increased in comparison with the un-induced condition (Figure 5), with 518-, 38-, 319-, and 99-fold increase, respectively. The differences of transcription level among $m n p A C, m n p B$ and $m n p D$ is likely due to that they were located on different operons and transcribed independently. Similarly, the mnp genes are also up-regulated under MNPinduced condition, with 407-, 53-, 279-, and 136-fold increase, respectively. This finding indicated that the mnp genes are likely responsible for both $2 \mathrm{C} 5 \mathrm{NP}$ and $\mathrm{MNP}$ catabolism in strain CNP-8.

\section{Expression and Purification of $\mathrm{mnp}$ Proteins}

A total of $34 \mathrm{mg}$ recombinant MnpA with specific activity of $33.6 \mathrm{U} \mathrm{mg}^{-1}$ for 2C5NP (47.5 $\mathrm{U} \mathrm{mg}^{-1}$ for MNP) was purified from $500 \mathrm{ml}$ of culture. Purified fractions of $\mathrm{H}_{6}-\mathrm{MnpA}$ were yellow, and the enzyme has absorption peaks at 370 and $450 \mathrm{~nm}$, consistent with previously reported flavoprotein nitroreductases (Somerville et al., 1995; Yin et al., 2010). For $\mathrm{H}_{6}$ MnpB purification, $25.4 \mathrm{mg}$ enzyme was obtained from $500 \mathrm{ml}$ of culture. Although a certain amount of $\mathrm{MnpC}$ was inclusion body, $4.2 \mathrm{mg}$ of $\mathrm{H}_{6}-\mathrm{MnpC}$ was purified from 3,000 $\mathrm{ml}$ of culture. Unfortunately, only a very small amount of $\mathrm{H}_{6}-\mathrm{MnpD}$ was soluble, and extremely little $\mathrm{H}_{6}-\mathrm{MnpD}$ was purified even 9,000

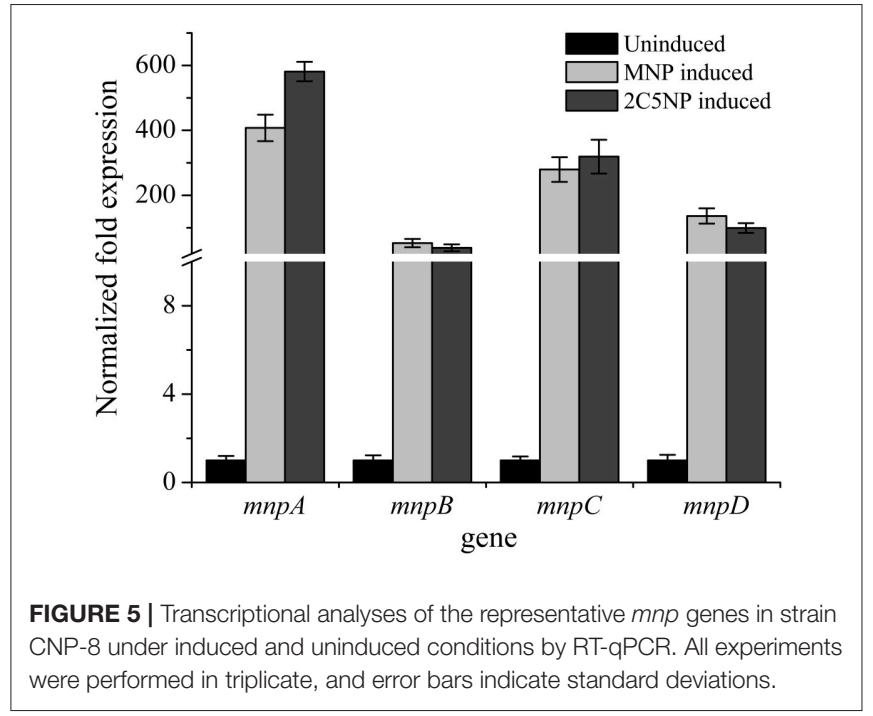

$\mathrm{ml}$ of culture was collected. SDS-PAGE analysis of the purified Mnp proteins showed that the molecular masses of $\mathrm{H}_{6}-\mathrm{MnpA}$, $\mathrm{H}_{6}-\mathrm{MnpB}$ and $\mathrm{H}_{6}-\mathrm{MnpC}$ are about 26, 52, and $35 \mathrm{kDa}$ (Figure $\mathrm{S} 2$ ), respectively, consistent with their deduced molecular masses.

\section{MnpA Catalyzes the Partial Reduction of 2C5NP to \\ 2-Chloro-5-Hydroxylaminophenol Via 2-Chloro-5-Nitrosophenol}

E. coli Rosetta(DE3) carrying pET-mnpA had the ability to degrade 2C5NP and MNP by HPLC analysis, whereas neither 2C5NP nor MNP consumption was detected when the E. coli cells only containing plasmid pET-28a. Furthermore, the purified $\mathrm{H}_{6}$ MnpA transformed MNP rapidly, together with the consumption 
of NADPH $\left(\lambda_{\max }=340 \mathrm{~nm}\right)$ and accumulation of a metabolite with a $\lambda_{\max }$ of $234 \mathrm{~nm}$ (Figure 6C), in accord with the spectral property of 3-hydroxylaminophenol as reported (Schenzle et al., 1999b). Previously, the MNP nitroreductase from Cupriavidus pinatubonensis JMP134 have been reported to catalyze the reduction of MNP (Yin et al., 2010), but its catalytic activity for $2 \mathrm{C} 5 \mathrm{NP}$ has not been characterized. In this study, $\mathrm{H}_{6}-\mathrm{MnpA}$ was found to be able to catalyze the degradation of $2 \mathrm{C} 5 \mathrm{NP}$, together with consumption of NADPH (Figure 6A). Two isobestic points at 232 and $254 \mathrm{~nm}$, respectively, were observed, suggesting the conversion of $2 \mathrm{C} 5 \mathrm{NP}$ to a new product $\left(\lambda_{\max } \approx 240 \mathrm{~nm}\right)$. In contrast, no spectral change occurred when His $_{6}-\mathrm{MnpA}$ was omitted from the reaction mixtures (Figures 6B,D).

By HPLC-MS analysis, two products with retention times of 12.84 and $13.16 \mathrm{~min}$, respectively, were detected when 2C5NP was transformed by purified $\mathrm{H}_{6}$-MnpA under anaerobic conditions (Figure 7A). Metabolite A $\left(\lambda_{\max }=230,298 \mathrm{~nm}\right)$ was suggested as 2-chloro-5-nitrosophenol, with a deprotonated ion at $m / z 156.14$ and its fragments at $m / z 125.89$ (loss of $-\mathrm{NO}$ ) and at $\mathrm{m} / z 139.23$ (loss of $-\mathrm{HO}$ ) (Figures $7 \mathbf{B}, \mathbf{C})$. Metabolite $\mathrm{B}\left(\lambda_{\max }\right.$ $=240,288 \mathrm{~nm}$ ) has the same spectral property with synthetic 2-chloro-5-hydroxylaminophenol (Schenzle et al., 1999b), which has a deprotonated ion at $m / z 158.03$ and the fragments at $m / z$
126.09 (loss of $-\mathrm{NHOH}$ ) and at $m / z 141.23$ (loss of $-\mathrm{HO}$ ) (Figures 7D,E). On the basis of the products identification of MnpA, strain CNP-8 was further proved to degrade $2 \mathrm{C} 5 \mathrm{NP}$ via a partial reductive pathway (Figure 4B), apart from the release of ammonium during 2C5NP degradation. The partialy-purified nitroreductase from Cupriavidus pinatubonensis JMP134 was previously proved to catalyze the transformation of 2C5NP to 2chloro-5-hydroxylaminophenol (Schenzle et al., 1999b), but its protein sequence and coding gene were not reported. Moreover, 2-chloro-5-nitrosophenol, the initial intermediate of microbial 2C5NP degradation, was detected for the first time in this study.

Neglectable activity of $\mathrm{H}_{6}-\mathrm{MnpA}$ for both 2C5NP and MNP was observed when NADPH in the reaction mixture was substituted by $\mathrm{NADH}$, indicating that MnpA prefers NADPH than NADH as the co-substrate, consistent with other reported nitroaromatic nitroreductases (Somerville et al., 1995; Yin et al., 2010). Enzymatic kinetics assays revealed that $\mathrm{H}_{6}-\mathrm{MnpA}$ exhibit a higher affinity and catalytic efficiency for $\mathrm{MNP}\left(K_{\mathrm{m}}=3.4 \pm\right.$ $1.63 \mu \mathrm{M}, k_{\text {cat }} / K_{\mathrm{m}}=342 \pm 47.6 \mu \mathrm{M}^{-1} \mathrm{~min}^{-1}$ ) than $2 \mathrm{C} 5 \mathrm{NP}$ $\left(K_{\mathrm{m}}=16.3 \pm 2.87 \mu \mathrm{M}, k_{\text {cat }} / K_{\mathrm{m}}=158 \pm 31.2 \mu \mathrm{M}^{-1} \mathrm{~min}^{-1}\right)$, suggested that MNP is the physiological substrate for MnpA in strain CNP-8.
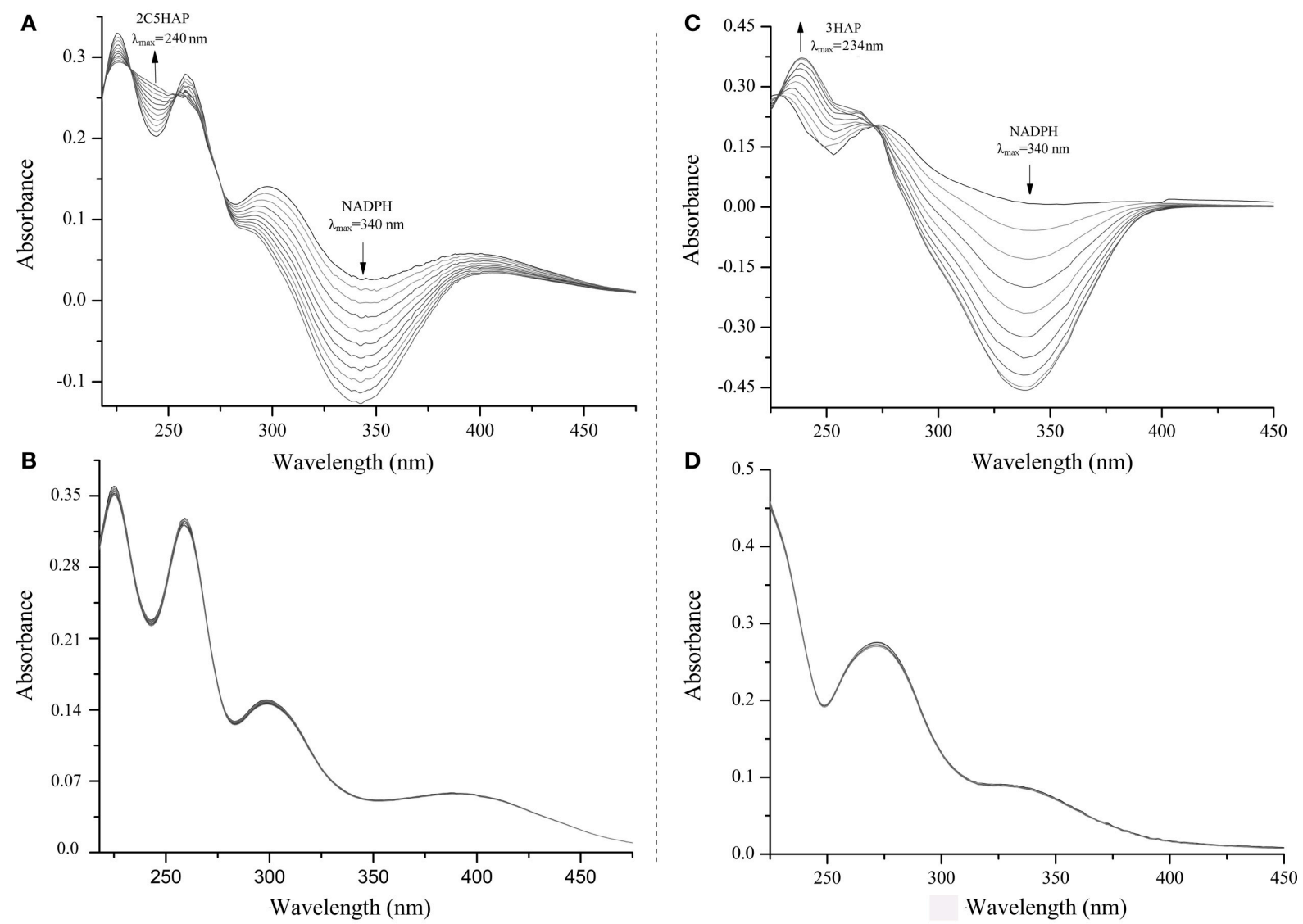

FIGURE 6 | Spectral changes during the transformation of 2C5NP (A: with $\mathrm{H}_{6}-\mathrm{PnpA}$; B: without $\left.\mathrm{H}_{6}-\mathrm{PnpA}\right)$ and MNP $\left(\mathbf{C}\right.$ : with $\mathrm{H}_{6}-\mathrm{PnpA}$; D: without $\left.\mathrm{H}_{6}-\mathrm{PnpA}\right)$. The spectra were recorded every minute after the addition of substrate. The arrows indicate the directions of spectral changes. 


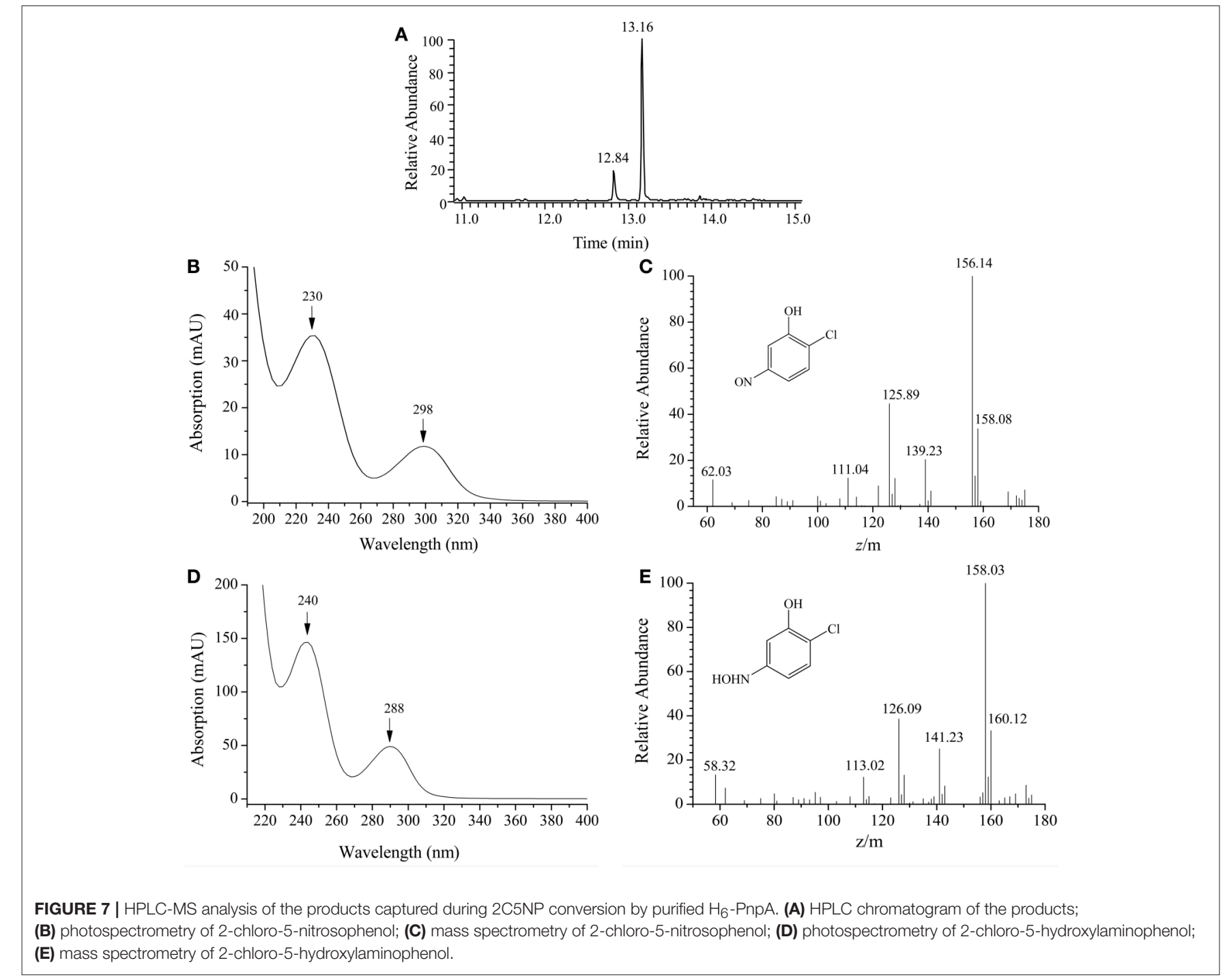

13.16

\section{MnpB, PnpC and MnpD Are Likely Involved in 2C5NP Catabolism in Strain CNP-8}

The enzymatic analysis of MnpB was not carried out in this study since the commercial standard of its substrate is unavailable. However, considering that $\mathrm{MnpB}$ exhibits extremely high degree of identity with the 3-hydroxylaminophenol mutase (accession number WP_011298219), which was capable to catalyze the transformation of synthetic 2-chloro-5-hydroxylaminophenol to 2-amino-5-chlorohydroquinone (Schenzle et al., 1999a), and its coding gene is highly transcribed in 2C5NP-induced strain CNP8; therefore, it is reasonable to conclude that $\mathrm{MnpB}$ is responsible for transformation of 2-chloro-5-hydroxylaminophenol to 2-amino-5-chlorohydroquinone during 2C5NP degradation by strain CNP-8 (Figure 4B). Purification of $\mathrm{H}_{6}-\mathrm{MnpD}$ failed, which hampered its enzymatic analysis in vitro. However, MnpD shares moderate identity (40\%) with LinD from Sphingomonas paucimobilis UT26 which was reported to catalyze dechlorination of 2,5-dichlorohydroquinone, a structure analog of 2-amino-5-chlorohydroquinone, to 2-chlorohydroquinone
(Kumari et al., 2002). Moreover, $m n p D$, located upstream of the 2C5NP nitroreductase-encoding mnpA, is up-regulated in 2C5NP-induced strain CNP-8. These combined data suggested that $\mathrm{MnpD}$ is lilely responsible for dechlorination of 2-amino-5-chlorohydroquinone to aminohydroquinone (Figure 4B).

Aminohydroquinone is extremely unstable (Schenzle et al., 1997; Yin and Zhou, 2010); therefore, its structure analogs chlorohydroquinone (CHQ) and hydroquinone (HQ) were used to identify the ring-cleavage function of $\mathrm{MnpC} . \mathrm{H}_{6}$ MnpC catalyzed rapid degradation of both CHQ and HQ, together with the accumulation of respective product with a $\lambda_{\max }$ of $320 \mathrm{~nm}$ (Figure S3). In contrast, neither substrate consumption nor product accumulation was observed when $\mathrm{His}_{6}$-MnpC was omitted from the reaction mixtures. Moreover, $m n p C$ was co-transcribed with mnpA in 2C5NP-induced strain CNP-8. Therefore, MnpC was likely involved in the ringcleavage reaction of 2C5NP degradation. So far, two kinds of (chloro)hydroquinone dioxygenase were reported. The linE-like 


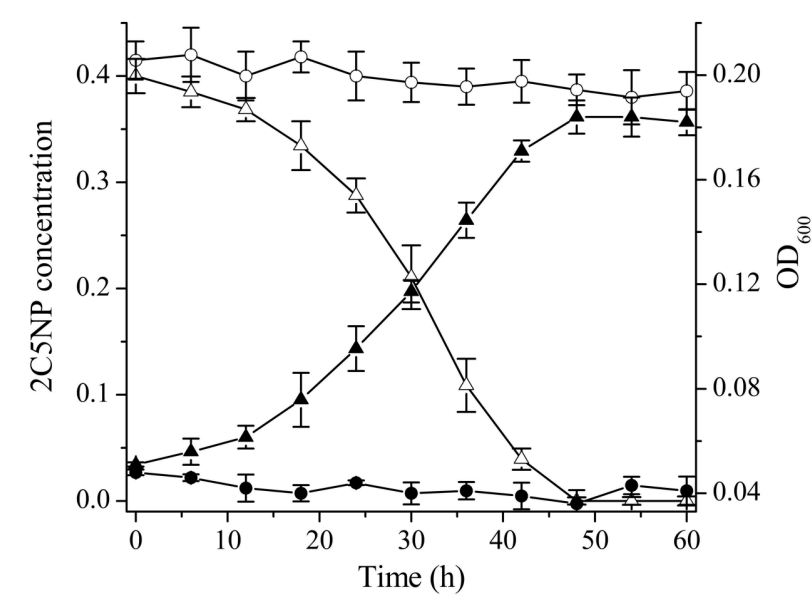

-O- $[2 \mathrm{C} 5 \mathrm{NP}]$ of CNP-8 $\triangle \mathrm{mnpA}-\mathrm{OD}_{600}$ of CNP-8 $\triangle \mathrm{mnpA}$

$-\triangle[2 \mathrm{C} 5 \mathrm{NP}]$ of CNP-8 $\Delta m n p A[\mathrm{pRK} 415-\mathrm{mnp} A]-\mathrm{OD}_{600}$ of CNP-8 $\triangle m n p A[\mathrm{pRK} 415-\mathrm{mnp} A]$

FIGURE 8 | Time course of 2C5NP degradation and cell growth of Cupriavidus sp. strains CNP-8 $\triangle m n p A$ (with mnpA deleted) and CNP-8 $\Delta m n p A[\mathrm{pRK} 415-m n p A]$ (with $m n p A$ complemented). The results of MNP are similar to $2 \mathrm{C} 5 \mathrm{NP}$, and they were not shown. All experiments were performed in triplicate, and error bars indicate standard deviations.

single-subunit dioxygenases were reported to split the ring of CHQ between C1 and C2 (Miyauchi et al., 1999; Ohtsubo et al., 1999), whereas the HapCD-like two-subunit dioxygenase catalyzed the ring cleavage of CHQ between $\mathrm{C} 1$ and $\mathrm{C6}$ (Moonen et al., 2008; Min et al., 2014). MnpC, a singlesubunit aminohydroquinone dioxygenases reported here exhibits moderate identity (42\%) with LinE, but has no sequence homology to HapCD. Therefore, the ring-cleavage position of aminohydroquinone catalyzed by $\mathrm{MnpC}$ during 2C5NP degradation was proposed between $\mathrm{C} 1$ and $\mathrm{C} 2$ with formation of 6-amino-4-hydroxy-6-oxohexa-2,4-dienoic acid (Figure 4B).

\section{mnpA Is Essential for 2C5NP Catabolism in Strain CNP-8}

To determine the involvement of MnpA in 2C5NP catabolism in vivo, a mutant of strain CNP-8 with substitution of $m n p A$ by a kanamycin resistant gene nptII was constructed through homologous recombination. Functional analysis showed that strain CNP-8 $\triangle m n p A$ (with $m n p A 1$ deleted) was no longer able to utilize $2 \mathrm{C} 5 \mathrm{NP}$ as well as MNP (Figure 8). This indicated that

\section{REFERENCES}

Ahmadi, E., Gholami, M., Farzadkia, M., Nabizadeh, R., and Azari, A. (2015). Study of moving bed biofilm reactor in diethyl phthalate and diallyl phthalate removal from synthetic wastewater. Bioresour. Technol. 183, 129-135. doi: 10.1016/j.biortech.2015.01.122

Arora, P. K. (2012). Decolourization of 4-chloro-2-nitrophenol by a soil bacterium, Bacillus subtilis RKJ 700. PLoS ONE 7:e52012. doi: 10.1371/journal.pone.0052012 $m n p A$ is necessary for strain CNP-8 to grow on both $2 \mathrm{C} 5 \mathrm{NP}$ and MNP. Although the mnpA1-complemented strain CNP$8 \Delta m n p A[\mathrm{pRK} 415-m n p A]$ regained the ability to utilize these two nitrophenols, it exhibited lower maximum degradation rate compared to the wild-type strain CNP-8 (Table 2).

\section{CONCLUSION}

Cupriavidus sp. strain CNP-8, the second bacterium with the ability to utilize $2 \mathrm{C} 5 \mathrm{NP}$, was isolated from pesticidecontaminated soil. Succinate was proved as the best additional carbon source during 2C5NP degradation by strain CNP-8. Biodegradation assays indicated that this strain is a potential and efficient candidate for biotreatment of 2C5NP-containing industrial effluents. MnpA catalyzes the partial reduction of $2 \mathrm{C} 5 \mathrm{NP}$ to 2-chloro-5-hydroxylaminophenol via 2-chloro5 -nitrosophenol which was firstly identified during 2C5NP catabolism, and its encoding gene is necessary for strain CNP8 to utilize 2C5NP. MnpC is likely responsible for the ringcleavage reaction of $2 \mathrm{C} 5 \mathrm{NP}$ degradation. This study fills a gap in the knoledge of the molecular mechanism of microbial 2C5NP degradation.

\section{AUTHOR CONTRIBUTIONS}

JM and XH designed the experiment, JM and JW performed the experiment, JM and WC analyzed data, JM and $\mathrm{XH}$ wrote the paper.

\section{ACKNOWLEDGMENTS}

This work was supported by the National Natural Science Foundation of China (No. 31600085), the National Key Research Program of China (No. 2016YFC1402300), the Foreword Key Priority Research Program of Chinese Academy of Sciences (No. QYZDB-SSW-DQC013), the Funding to Jun Min by State Key Laboratory of Microbial Metabolism, Shanghai JiaoTong University (MMLKF15-04).

\section{SUPPLEMENTARY MATERIAL}

The Supplementary Material for this article can be found online at: http://journal.frontiersin.org/article/10.3389/fmicb. 2017.01778/full\#supplementary-material 
Arora, P. K., and Jain, R. K. (2012b). Biotransformation of 4-chloro-2-nitrophenol into 5-chloro-2-methylbenzoxazole by a marine Bacillus sp strain MW-1. Biodegradation 23, 325-331. doi: 10.1007/s10532-011-9512-y

Arora, P. K., Sasikala, C., and Ramana Ch, V. (2012a). Degradation of chlorinated nitroaromatic compounds. Appl. Microbiol. Biotechnol. 93, 2265-2277. doi: 10.1007/s00253-012-3927-1

Arora, P. K., Sharma, A., Mehta, R., Shenoy, B. D., Srivastava, A., and Singh, V. P. (2012b). Metabolism of 4-chloro-2-nitrophenol in a grampositive bacterium, Exiguobacterium sp. PMA. Microb. Cell Fact. 11, 150. doi: 10.1186/1475-2859-11-150

Arora, P. K., Srivastava, A., and Singh, V. P. (2014a). Bacterial degradation of nitrophenols and their derivatives. J. Hazard. Mater. 266, 42-59. doi: 10.1016/j.jhazmat.2013.12.011

Arora, P. K., Srivastava, A., and Singh, V. P. (2014b). Degradation of 4-chloro-3nitrophenol via a novel intermediate, 4-chlororesorcinol by Pseudomonas sp. JHN. Sci. Rep. 4:4475. doi: 10.1038/srep04475

Bradford, M. M. (1976). A rapid and sensitive method for the quantitation of microgram quantities of protein utilizing the principle of proteindye binding. Anal. Biochem. 72, 248-254. doi: 10.1016/0003-2697(76) 90527-3

Bruhn, C., Bayly, R. C., and Knackmuss, H. J. (1988). The in vivo construction of 4-chloro-2-nitrophenol assimilatory bacteria, Arch. Microbiol. 150, 171-177.

Carmichael, L. M., and Pfaender, F. K. (1997). The effect of inorganic and organic supplements on the microbial degradation of phenanthrene and pyrene in soils. Biodegradation 8, 1-13. doi: 10.1023/A:1008258720649

Chen, Y. F., Chao, H., and Zhou, N. Y. (2014). The catabolism of 2,4-xylenol and $p$-cresol share the enzymes for the oxidation of para-methyl group in Pseudomonas putida NCIMB 9866. Appl. Microbiol. Biotechnol. 98, 1349-1356. doi: 10.1007/s00253-013-5001-z

Cheung, P. Y., and Kinkle, B. K. (2005). Effects of nutrients and surfactants on pyrene mineralization and Mycobacterium spp. populations in contaminated soil. Soil. Biol. Biochem. 37, 1401-1405. doi: 10.1016/j.soilbio.2004. 12.008

Chi, X. Q., Zhang, J. J., Zhao, S., and Zhou, N. Y. (2013). Bioaugmentation with a consortium of bacterial nitrophenol-degraders for remediation of soil contaminated with three nitrophenol isomers. Environ. Pollut. 172, 33-41. doi: 10.1016/j.envpol.2012.08.002

Deng, Y., Mao, Y., Li, B., Yang, C., and Zhang, T. (2016). Aerobic degradation of sulfadiazine by Arthrobacter spp.: kinetics, pathways, and genomic characterization. Environ. Sci. Technol. 50, 9566-9575. doi: 10.1021/acs.est.6b02231

Fang, H. H., Liang, D., and Zhang, T. (2007). Aerobic degradation of diethyl phthalate by Sphingomonas sp. Bioresour. Technol. 98, 717-720. doi: 10.1016/j.biortech.2006.02.010

Ghosh, A., Khurana, M., Chauhan, A., Takeo, M., Chakraborti, A. K., and Jain, R. K. (2010). Degradation of 4-nitrophenol, 2-chloro-4-nitrophenol, and 2,4dinitrophenol by Rhodococcus imtechensis strain RKJ300. Environ. Sci. Technol. 44, 1069-1077. doi: 10.1021/es9034123

Jaoui, M., Achard, C., and Rogalski, M. (2002). Solubility as a function of temperature of selected chlorophenols and nitrophenols in aqueous solutions containing electrolytes or surfactants. J. Chem. Eng. Data 47, 297-303. doi: $10.1021 /$ je0102309

Krug, F. J., Ruzicka, J., and Hansen, E. H. (1979). Determination of ammonia in low concentrations with nesslers reagent by flow injection analysis. Analyst 104, 47-54. doi: 10.1039/an9790400047

Kumari, R., Subudhi, S., Suar, M., Dhingra, G., Raina, V., Dogra, C., et al. (2002). Cloning and characterization of lin genes responsible for the degradation of Hexachlorocyclohexane isomers by Sphingomonas paucimobilis strain B90. Appl. Environ. Microbiol. 68, 6021-6028. doi: 10.1128/AEM.68.12.6021-6028.2002

Liu, H., Wang, S. J., Zhang, J. J., Dai, H., Tang, H., and Zhou, N. Y. (2011). Patchwork assembly of nag-like nitroarene dioxygenase genes and the 3chlorocatechol degradation cluster for evolution of the 2-chloronitrobenzene catabolism pathway in Pseudomonas stutzeri ZWLR2-1. Appl. Environ. Microbiol. 77, 4547-4552. doi: 10.1128/AEM.02543-10

Liu, H., Wang, S. J., and Zhou, N. Y. (2005). A new isolate of Pseudomonas stutzerithat degrades 2-chloronitrobenzene. Biotechnol. Lett. 27, 275-278. doi: $10.1007 /$ s10529-004-8293-3
Liu, T. T., and Zhou, N. Y. (2012). Novel L-cysteine-dependent maleylpyruvate isomerase in the gentisate pathway of Paenibacillus sp. strain NyZ101. J. Bacteriol. 194, 3987-3994. doi: 10.1128/JB.00050-12

Livak, K. J., and Schmittgen, T. D. (2001). Analysis of relative gene expression data using real-time quantitative PCR and the $2^{-\Delta \Delta C T}$ Method. Methods 25, 402-408. doi: 10.1006/meth.2001.1262

Min, J., Lu, Y., Hu, X. K., and Zhou, N. Y. (2016a). Biochemical characterization of 3-methyl-4-nitrophenol degradation in Burkholderia sp. strain SJ98. Front. Microbiol. 7:791. doi: 10.3389/fmicb.2016.00791

Min, J., Wang, B., and Hu, X. K. (2017). Effect of inoculation of Burkholderia sp. strain SJ98 on bacterial community dynamics and para-nitrophenol, 3-methyl4-nitrophenol, and 2-chloro-4-nitrophenol degradation in soil. Sci. Rep. 7, 5983. doi: 10.1038/s41598-017-06436-0

Min, J., Zhang, J. J., and Zhou, N. Y. (2014). The gene cluster for paranitrophenol catabolism is responsible for 2-chloro-4-nitrophenol degradation in Burkholderia sp. strain SJ98. Appl. Environ. Microbiol. 80, 6212-6222. doi: 10.1128/AEM.02093-14

Min, J., Zhang, J. J., and Zhou, N. Y. (2016b). A two-component para-nitrophenol monooxygenase initiates a novel 2-chloro-4-nitrophenol catabolism pathway in Rhodococcus imtechensis RKJ300. Appl. Environ. Microbiol. 82, 714-723. doi: 10.1128/AEM.03042-15

Miyauchi, K., Adachi, Y., Nagata, Y., and Takagi, M. (1999). Cloning and sequencing of a novel meta-cleavage dioxygenase gene whose product is involved in degradation of gamma-hexachlorocyclohexane in Sphingomonas paucimobilis. J. Bacteriol. 181, 6712-6719.

Moonen, M. J., Synowsky, S. A., van den Berg, W. A., Westphal, A. H., Heck, A. J., van den Heuvel, R. H., et al. (2008). Hydroquinone dioxygenase from pseudomonas fluorescens ACB: a novel member of the family of nonheme-iron(II)-dependent dioxygenases. J. Bacteriol. 190, 5199-5209. doi: 10.1128/JB.01945-07

Ohtsubo, Y., Miyauchi, K., Kanda, K., Hatta, T., Kiyohara, H., Senda, T., et al. (1999). PcpA, which is involved in the degradation of pentachlorophenol in Sphingomonas chlorophenolica ATCC39723, is a novel type of ring-cleavage dioxygenase. FEBS Lett. 459, 395-398. doi: 10.1016/S0014-5793(99)01305-8

Pandey, J., Heipieper, H. J., Chauhan, A., Arora, P. K., Prakash, D., Takeo, M., et al. (2011). Reductive dehalogenation mediated initiation of aerobic degradation of 2-chloro-4-nitrophenol (2C4NP) by Burkholderia sp. strain SJ98. Appl. Microbiol. Biotechnol. 92, 597-607. doi: 10.1007/s00253-011-3254-y

Polz, M. F., and Cavanaugh, C. M. (1998). Bias in template-to-product ratios in multitemplate PCR. Appl. Environ. Microbiol. 64, 3724-3730.

Pradhan, A. C., Nanda, B., Parida, K. M., and Das, M. (2013). Quick photoFenton degradation of phenolic compounds by $\mathrm{Cu} / \mathrm{Al}_{2} \mathrm{O}_{3}-\mathrm{MCM}-41$ under visible light irradiation: small particle size, stabilization of copper, easy reducibility of $\mathrm{Cu}$ and visible light active material. Dalton Trans. 42, 558-566. doi: 10.1039/C2DT32050A

dos Santos, V. L., Monteiro, A. D., Braga, D. T., and Santoro, M. M. (2009). Phenol degradation by Aureobasidium pullulans FE13 isolated from industrial effluents. J. Hazard. Mater. 161, 1413-1420. doi: 10.1016/j.jhazmat.2008.04.112

Schenzle, A., Lenke, H., Fischer, P., Williams, P. A., and Knackmuss, H. (1997). Catabolism of 3-nitrophenol by Ralstonia eutropha JMP 134. Appl. Environ. Microbiol. 63, 1421-1427.

Schenzle, A., Lenke, H., Spain, J. C., and Knackmuss, H. J. (1999a). 3Hydroxylaminophenol mutase from Ralstonia eutropha JMP134 catalyzes a Bamberger rearrangement. J. Bacteriol. 181, 1444-1450.

Schenzle, A., Lenke, H., Spain, J. C., and Knackmuss, H. J. (1999b). Chemoselective nitro group reduction and reductive dechlorination initiate degradation of 2chloro-5-nitrophenol by Ralstonia eutropha JMP134. Appl. Environ. Microbiol. $65,2317-2323$.

Shen, J., He, R., Wang, L., Zhang, J., Zuo, Y., Li, Y., et al. (2009). Biodegradation kinetics of picric acid by Rhodococcus sp.NJUST16 in batch reactors. J. Hazard. Mater. 167, 193-198. doi: 10.1016/j.jhazmat.2008.12.100

Somerville, C. C., Nishino, S. F., and Spain, J. C. (1995). Purification and characterization of nitrobenzene nitroreductase from Pseudomonas pseudoalcaligenes JS45. J. Bacteriol. 177, 3837-3842. doi: 10.1128/jb.177.13.3837-3842.1995

Tiwari, J., Naoghare, P., Sivanesan, S., and Bafana, A. (2017). Biodegradation and detoxification of chloronitroaromatic pollutant by Cupriavidus. Bioresour. Technol. 223, 184-191. doi: 10.1016/j.biortech.2016.10.043 
Wang, L. M., Chi, X. Q., Zhang, J. J., Sun, D. L., and Zhou, N. Y. (2014). Bioaugmentation of a methyl parathion contaminated soil with Pseudomonas sp. strain WBC-3. Int. Biodeter. Biodegr. 87, 116-121. doi: 10.1016/j.ibiod.2013.11.008

Xiao, Y., Wu, J. F., Liu, H., Wang, S. J., Liu, S. J., and Zhou, N. Y. (2006). Characterization of genes involved in the initial reactions of 4-chloronitrobenzene degradation in Pseudomonas putida ZWL73. Appl. Microbiol. Biotechnol. 73, 166-171. doi: 10.1007/s00253-006-0441-3

Xiao, Y., Zhang, J. J., Liu, H., and Zhou, N. Y. (2007). Molecular characterization of a novel ortho-nitrophenol catabolic gene cluster in Alcaligenes sp. strain NyZ215. J. Bacteriol. 189, 6587-6593. doi: 10.1128/JB.00654-07

Yin, Y., Xiao, Y., Liu, H. Z., Hao, F., Rayner, S., Tang, H., et al. (2010). Characterization of catabolic meta-nitrophenol nitroreductase from Cupriavidus necator JMP134. Appl. Microbiol. Biotechnol. 87, 2077-2085. doi: 10.1007/s00253-010-2666-4

Yin, Y., and Zhou, N. Y. (2010). Characterization of MnpC, a hydroquinone dioxygenase likely involved in the meta-nitrophenol degradation by Cupriavidus necator JMP134. Curr. Microbiol. 61, 471-476. doi: 10.1007/s00284-010-9640-3

Zhang, J. J., Liu, H., Xiao, Y., Zhang, X. E., and Zhou, N. Y. (2009). Identification and characterization of catabolic para-nitrophenol 4-monooxygenase and para-benzoquinone reductase from Pseudomonas sp. strain WBC-3. J. Bacteriol. 191, 2703-2710. doi: 10.1128/JB.01566-08

Zhang, J., Sun, Z., Li, Y., Peng, X., Li, W., and Yan, Y. (2009). Biodegradation of p-nitrophenol by Rhodococcus sp. CN6 with high cell surface hydrophobicity. J. Hazard. Mater. 163, 723-728. doi: 10.1016/j.jhazmat.2008. 07.018

Zhong, Y., Luan, T., Wang, X., Lan, C., and Tam, N. F. (2007). Influence of growth medium on cometabolic degradation of polycyclic aromatic hydrocarbons by Sphingomonas sp. strain PheB4. Appl. Microbiol. Biotechnol. 75, 175-186. doi: 10.1007/s00253-006-0789-4

Conflict of Interest Statement: The authors declare that the research was conducted in the absence of any commercial or financial relationships that could be construed as a potential conflict of interest.

Copyright (c) 2017 Min, Chen, Wang and Hu. This is an open-access article distributed under the terms of the Creative Commons Attribution License (CC BY). The use, distribution or reproduction in other forums is permitted, provided the original author(s) or licensor are credited and that the original publication in this journal is cited, in accordance with accepted academic practice. No use, distribution or reproduction is permitted which does not comply with these terms. 